\title{
Altimetric Calibration Experiences in the Western Mediterranean
}

\author{
J.J. Martinez-Benjamin, M. Martinez Garcia \\ Dpt. Geotechnical Engineering and Geosciences 1 \\ LTechnical University of Catalonia (UPC) \\ Barcelona, Spain \\ jj.benjamin@upc.edu
}

\author{
M.A. Ortiz Castellon, Julia Talaya, Anna Baron \\ Cartographic Institute of Catalonia \\ Barcelona, Spain
}

\author{
P. Bonnefond \\ GEMINI/GRGS \\ Observatoire de la Cote d'Azur \\ Grasse, France
}

\begin{abstract}
Since many years, space borne radar altimeters have brought a powerful contribution in monitoring the dynamic sea surface topography, and in understanding better the ocean circulation and its impact on the earth system. Today, altimetric satellites are observing the whole oceans, measuring the sea surface height with a rms precision of 3-4 cm at $1 \mathrm{~Hz}$ sampling, as demonstrated by TOPEX/POSEIDON, launched in 1992, by Jason-1, launched in 2001 and by ENVISAT, launched in 2002.

Such a high level error budget was achieved thanks to the tremendous improvements which have been obtained in radar performances as well as in precise orbit determination. Indeed, applications of altimetry in oceanography and geodesy requires very precise measurements of the satellite-sea level range, along with appropriate environmental corrections, but also an accurate knowledge of the satellite position with respect to the Earth reference.
\end{abstract}

One campaign has also been made in June 2003 at the Ibiza island area (Martinez-Benjamin et al., 2003). The marine geoid has been used to relate the coastal tide gauge data from Ibiza and San Antonio harbours to off-shore altimetric data. A technical Spanish contribution to the calibration experience has been the design of GPS buoys and GPS catamaran taking in account the University of Colorado at Boulder and Senetosa/Capraia designs.

We present a synthesis of the sea level results results obtained from the altimeter calibration campaign at Ibiza island on June 2003 using the direct measurements from GPS buoys and the derived marine geoid. The main objective of the marine campaign was to check the value of Ibiza Island as a permanent calibration site in the western Mediterranean Sea, to complement the Corsica site in the network of altimeter calibration sites.

\author{
J. Martin Davila, J. Garate \\ Real Instituto y Observatorio de la Armada (ROA) \\ San Fernando, Cadiz, Spain
}

G. Rodriguez Velasco

Universidad Complutense de Madrid

Madrid, Spain

\author{
B. Perez
}

Puertos del Estado (PE)

Madrid, Spain
Keywords: altimeter calibration, GPS buoys, Tidegauges, geoid

\section{INTRODUCTION}

Since many years, space borne radar altimeters have brought a powerful contribution in monitoring the dynamic sea surface topography, and in understanding better the ocean circulation and its impact on the earth system. Today, altimetric satellites are observing the whole oceans, measuring the sea surface height with a rms precision of $3-4 \mathrm{~cm}$ at $1 \mathrm{~Hz}$ sampling, as demonstrated by TOPEX/POSEIDON, launched in 1992, by Jason-1, launched in 2001 and by ENVISAT, launched in 2002. Such a high level error budget was achieved thanks to the tremendous improvements which have been obtained in radar performances as well as in precise orbit determination. Indeed, applications of altimetry in oceanography and geodesy requires very precise measurements of the satellite-sea level range, along with appropriate environmental corrections, but also an accurate knowledge of the satellite position with respect to the Earth reference.

Three Begur Cape experiences on radar altimeter calibration and marine geoid mapping were made on 1999, 2000 and 2002. The first Spanish 1999 campaign using a GPS buoy included the first direct absolute altimeter calibration of TOPEX Altimeter Site B in the western Mediterranean (Fig. 1). 
The GPS buoys used in the calibration campaigns were designed and builded at the Cartographic Institute of Catalonia using an original design from the University of Colorado at Boulder improving the stability and minimaxing the distance between the sea surface and the center of phase of the antenna.

The models follows some functional requirements as to offer protection to the GPS antenna against the sea water, bad sea conditions and any eventual accident. The radome must allow the GPS signal reception with a minimum disturbance. The buoy was provided with a TRIMBLE DORNE MARGOLIN antenna and connected to the receiver on the boat by a coaxial watertight cable.

With respect the monument and instrumentation of the l'Estartit tide gauge, the installation is a traditional floating gauge placed in the inner wall of l'Estartit harbor (Fig. 2). It provides with sea level measurements every 2 hours. The accuracy of the height measurements is about $2 \mathrm{~mm}$.

The GPS observables from a network consisted of three permanent CATNET ICC stations (Bellmunt de la Segarra, BELL,; Creus Cape, CREU, and Llivia, LLIV), and the temporal site in the coast (stations at Begur Cape, Aiguablava and Palamos) and were processed following a free-network solution strategy with the GIPSY-OASIS II software developed by JPL.

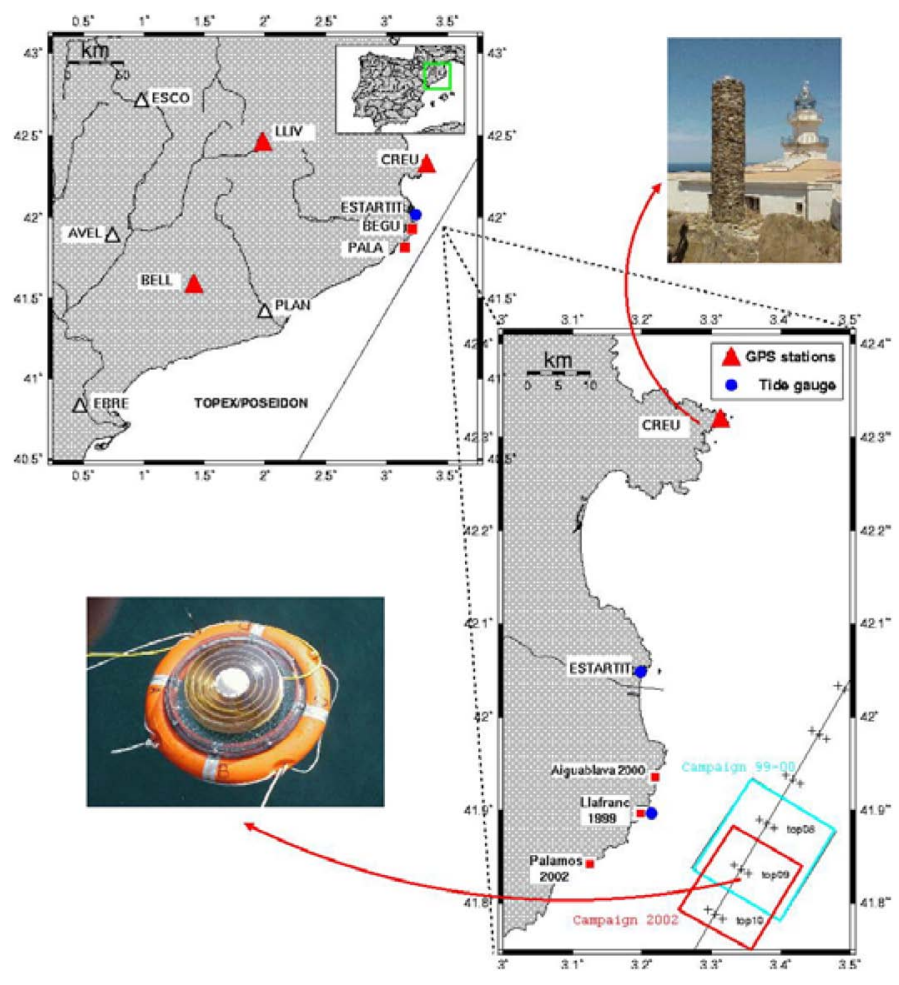

Figure 1: Cape of Begur altimeter calibration site showing the locations of Begur, Aiguablava and Palamos where was established a temporal GPS reference station in the 1999, 2000 and 2002 campaigns.

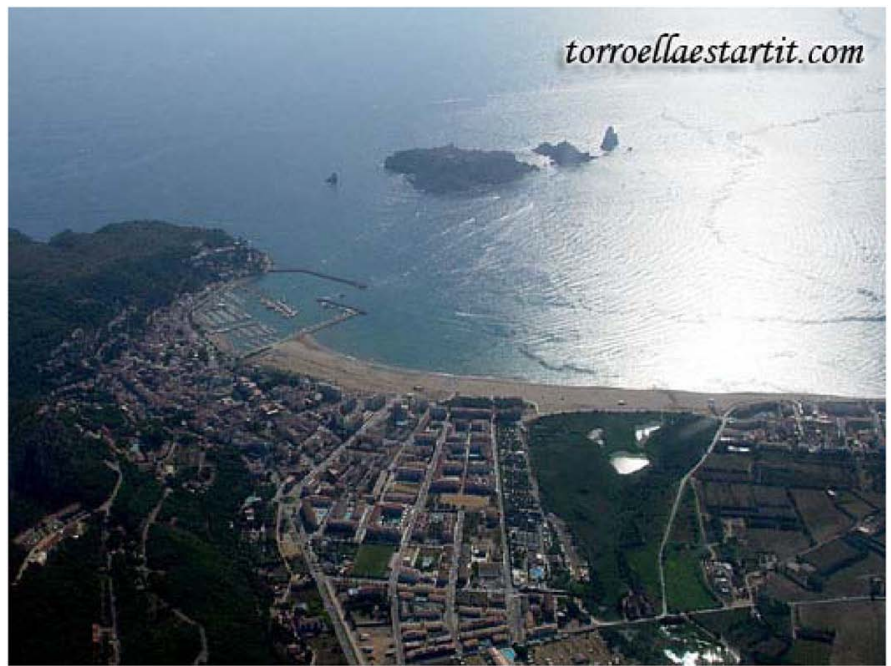

Figure 2: L'Estartit town

\section{IBIZA ALTIMETER CALIBRATION SITE}

A Spanish JASON-1 calibration campaign, IBIZA 2003, was carried out in June 9-17, 2003 in the area of Ibiza Island in the NW Mediterranean Sea. The objective of the campaign was to map the instantaneous sea level/local geoid gradient in three areas around Ibiza: at the crossing point of an ascending and descending JASON-1 tracks located to the north of the island, and along these tracks to the SE and SW of the Island.

A major component of the IBIZA2003 campaign, made in June 2003, was a newly designed, calibrated GPS catamaran built up at ICC, following the original design from Senetosa experiences (Bonnefond et al., 2003a). It was towed by the Spanish Navy Patrol Deva, with a crew of 17 persons on board plus researchers from ROA, UPC and GEMINI. A zodiac from the Spanish Navy was also used to deploy a light wave-rider GPS buoy at Ibiza and San Antonio harbours. The objective was to provide instantaneous geocentric sea-level measurements with the instantaneous nearby GPS data obtained with the catamaran (an optical levelling was carried out in both harbours). A direct altimeter absolute calibration was made (on June 14) with the catamaran and the GPS buoy near the crossover point located to the north of the island.

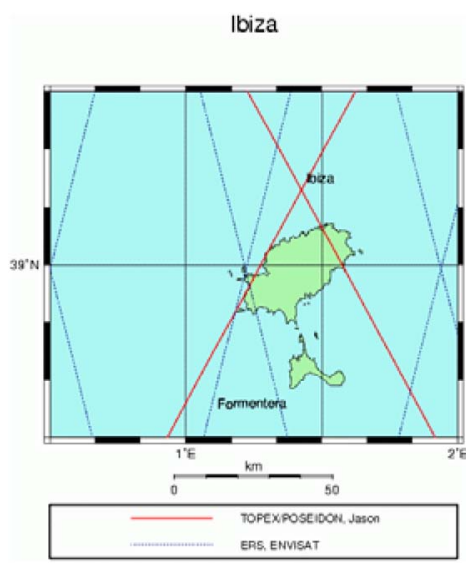

Figure 3: Ibiza island 
Five GPS reference stations were deployed on Ibiza Island: one at Portinatx (PORT- Leica antenna and receiver), two at San Antonio (SANA- Astech antenna and receiver type, and SANB- Topcon antenna and receiver type) and two at Ibiza (IBIA- Trimble antenna and Astech receiver, and IBIB-Leica antenna and receiver type) (Fig. 3). For IBIA, SANA and SANB stations, the raw data set covered 6 days (11-16 June 2003), whereas for IBIB and PORT stations it covered only 5 days. The sample rate was fixed to 30 seconds except during the Catamaran/Buoy measurements, during when it was set to 1 second.

The Spanish Port Authority, Puertos del Estado installed the pressure tide gauge station of Ibiza harbour in January 2003 (Fig. 5). The station belongs to the REDMAR network, composed at this moment by 21 stations distributed along the whole Spanish waters.

A levelling made on December 3, 2004 allowed to make a levelling with the Digital Level NA2002 between the TGBM (Tide Gauge Bench Mark) near the Ibiza pressure tide gauge and the GPS station placed in the roof of the Director's building of Marina de Botafoch (Fig. 4). The CGPS belongs to Puertos del Estado.

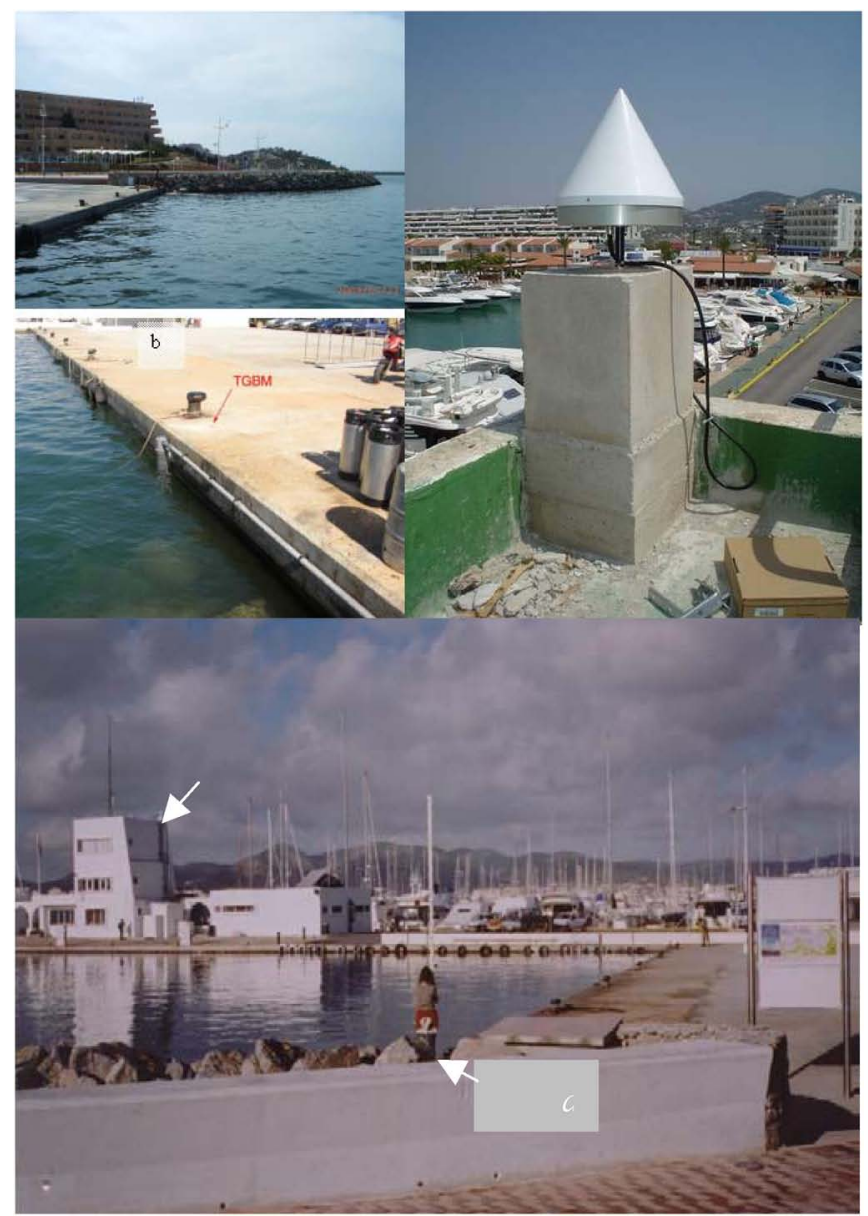

Figure 4: Location of the tide gauge and the GPS reference station at the Marina de Botafoch harbour. The arrows indicate the location of the GPS antenna and the tide gauge.
For the GPS Reference Stations using the static analysis, were used three software/methodologies: Bernese (computation by ICC), GIPSY-OASIS II (computation by ROA) and GAMIT/GLOBK (computation by OCA-GEMINI). All these solutions are based on $30 \mathrm{~s}$ time sampling GPS data.

The kinematic solutions are based on the high rate GPS data $(1 \mathrm{~Hz})$. The area covered by the catamaran represents a huge amount of GPS data. The mobile receivers (Catamaran and buoy) ellipsoidal heights are solved relatively to the coordinates of the reference stations chosen in the previous section (OCA-GEMINI solution). This processing has been realized independently by ICC (POSGPS Software) and OCAGEMINI (TRACK software).

\section{A. OCA-GEMINI Solution}

The kinematic solution was processed using TRACK software developed at MIT (Herring 2002b). Details on the TRACK processing and standards can be found in Watson et al. (2003). In order to reduce the impact of distance in the kinematic GPS processing SANA, IBIB and PORT have been chosen as reference stations (fixed) and CATL and CATR have been processed independently. IBIB has been chosen instead of IBIA because it was equipped with the same antenna/receiver than CATR.

However, there were lots of data gap for the Leica receiver (CATR) and also lots of satellite lost so the solution was very difficult to process and results were very uncertain because of too few fixed ambiguities. We have then decided to use only the CATL solution for processing the GPS sea level map.

\section{B. ICC Solution}

For computing GPS kinematic sessions ICC used POSGPS v4.02 software, from Applanix. The computation of each trajectory was done in three steps: a forward filtering (positive in time), a backward filtering (negative in time) and a final combination of the two previous processes (smoothing), assigning weights at each epoch according to certain quality parameters. This software has also the possibility to combine different solutions computed from several GPS permanent stations.

\section{Sea height processing}

The chosen boat velocity was about $4.2 \mathrm{~m} / \mathrm{s},(\sim 8 \mathrm{knots})$ so the cut-off period in the time domain has been chosen to be $400 \mathrm{~s}(\sim 1.7 \mathrm{~km}$ in the space domain) in order to homogenize along-track and across-track $(\sim 2 \mathrm{~km})$ wavelengths. This filtering also allows reducing the high frequency sea level variations due to both GPS processing uncertainty and sea state.

For the data editing a global velocity criteria (between 3.7 and $4.7 \mathrm{~m} / \mathrm{s}$ ) has been chosen in order to avoid speeddependent sea-height variations. Some parts of the solutions have been also excluded due to very poor results for both ICC and OCA-GEMINI solution (large crossover values, rms, ...): the longer period removed is for the long diagonal of the south west area because the boat have to be stopped to reinforced the towing rope; in fact during this period the GPS cable were too tense and the connector were unscrewed leading to many 
satellite lost. From a total of 158400 only 74505 GPS data have been kept for the final solution; the eliminated data mostly correspond to the transits between the harbours and the area of interest (59103 GPS data) during which the boat velocity was about 10 knots $(\sim 5 \mathrm{~m} / \mathrm{s})$.

In Fig. 5, it is showed the contour map of the gridded GPS sea surface heights (weighted mean) obtained from the catamaran marine campaign (with the use of the barotropic model MOG2D from LEGOS). Dashed lines represent the Jason-1 passes: ascending $\mathrm{N}^{\circ} 187$ (South West - North East) and descending $\mathrm{N}^{\circ} 248$ (North West - . South East). The extended explanation can be seen in [4].
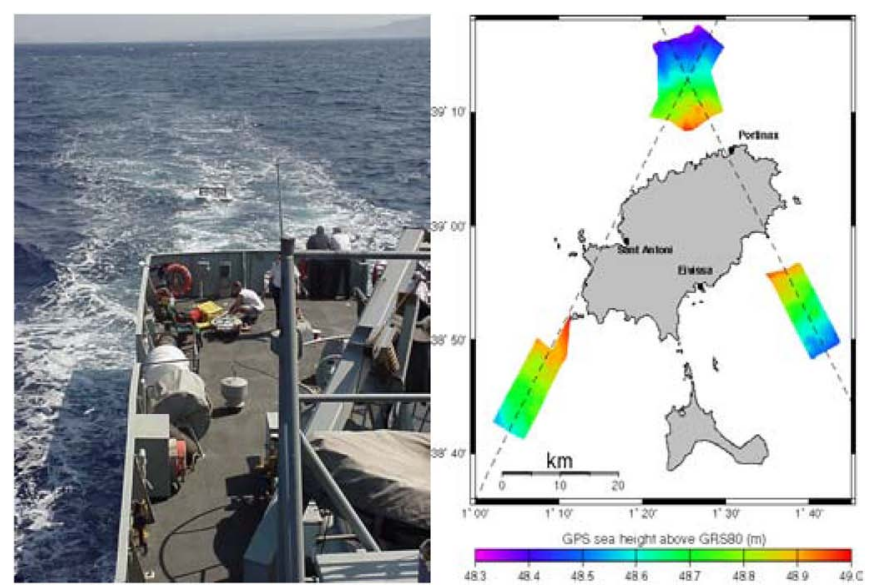

Fig.5: GPS catamaran towed by the patrol and mapping the areas around Ibiza where GPS stations were located in Ibiza, San Antonio and Portinatx, and GPS sea surface heights over GRS80.

\section{RESULTS OF THE IBIZA CAMPAIGN}

The main objective was to test the value of Ibiza Island [4] as a possible permanent calibration site in the western Mediterranean Sea, to complement to the Corsica/Senetosa site and other CalVal sites around the world $[1,2,3,5,6,7,8]$.

Indeed, more dedicated calibration sites, as Ibiza or San Antonio, can help to control the geographically correlated errors that are significant at single sites.

The overall precision of the resulting "marine geoid" is estimated to be at the level of $3 \mathrm{~cm}$ rms.

The altimeter biases are given in table I, presented at the CalVal meeting in Venice 2006 by P. Bonnefond.
Table I: Altimeter biases

\begin{tabular}{|c|c|c|c|c|}
\hline Site & GDR- $-i(\mathrm{~mm})$ & GDR-E $(3 m+1)$ & Number of cycles & Reference \\
\hline Hayาest' & $+1+1.8 \pm 6,3$ & $+97,4 \div ? .4$ & $108: 29$ & Foines at w! \\
\hline Corsica' & $+107.9 \pm 6.7$ & $+86.3 \pm 8.6$ & $84 ; 21$ & Boringrowd et al. \\
\hline Bass Strait & $+1.5 \geq .3 \div 7.7$ & $+105.0 \pm 8.3$ & $19: 18$ & Watsmatal. \\
\hline Gandos & $+1.11 .0 \doteq 15$ & $\mathrm{NA}$ & $16 ; \sqrt[3 A]{ }$ & Hovis a of oi \\
\hline bliza & $+\mathrm{l} 200.5 \pm+.4$ & NA & $A B: 3 A$ & 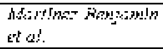 \\
\hline Rtzgivunal & $1100.0 \div 1.0$ & 91.018 .0 & $21: 21$ & Vurfiel all. \\
\hline
\end{tabular}

\section{ACKNOWLEDGMENT}

These campaigns were supported by the Spanish Ministery of Science and Technology under projects of the National Space Program ref: ESP1997-1816-CO4-03 and ESP20014534-PE.

IBIZA2003 TEAM: Cristina Garcia, Enrique Alvarez, Sergio Gonzalez, Amparo Nuñez, Felipe Buill, Jaime LopezMarco, Manuel Espino, Damia Gomis, Marta Marcos, Yves Menard, Florent Lyard, Olivier Laurain, Gwenaele Jan, Eric Jeansou, Laurent Roblou, Marta Sastre, Miriam Moysset, Ana Serrano.

\section{REFERENCES}

[1] P. Bonnefond, P.Exertier, O. Laurain, Y. Menard, A. Orsoni, E. Jeansou, B. Haines, D. Kubitshek and G. Born, "Levelling Sea Surface using a GPS catamaran", Marine Geodesy, 26(3-4), 2003, 319-334.

[2] G.H. Born, M.E. Parke, P. Axelrad, K.L. Gold, J. Johnson, K.W. Key and D. Kubitscheck, "Calibration of the Topex altimeter using a GPS buoy". J. Geophys. Res. 99(C12), 1994, 24517-24526.

[3] B.J. Haines, D. Dong, G.H. Born, and S.K. Gill, "The Harvest experiment: Monitoring Jason-1 and TOPEX/POSEIDON from a California offshore platform", Marine Geodesy, 26(3-4), 2003, 239-259.

[4] J.J. Martinez Benjamin, M. Martinez, S. Gonzalez, A. Nuñez, F. Buill, M. Espino, J. Lopez, J. Martin Davila, J. Garate, C. Garcia, P. Bonnefond, O. Laurain, A. Baron, M.A. Ortiz Castellon, J. Talaya, B. Perez, E. Alvarez, G. Rodriguez Velasco, D. Gomis, M. Marcos, Y. Menard, G. Jan, E. Jeansou, F. Lyard and L. Roblou."Ibiza Absolute Calibration Experiment: Survey and preliminary Results", Marine Geodesy, 27(3-4), 2004, 657-68.

[5] E.C. Pavlis and the GAVDOS Team, "The GAVDOS Mean Sea Level and Altimeter Calibration Facility: Results for Jason-1", Marine geodesy, 27(3-4), 2004, 631-655

[6] C.K. Shum, Y. Yi, K. Cheng, C. Kuo, A. Braun, S. Calmant and D. Chambers, "Calibration of Jason-1 Altimeter over Lake Eire", Marine Geodesy, 26(3-4), 2003, 335-354.

[7] C. Watson, R. Coleman, N. White, J. Church and R. Govind, "Absolute Calibration of TOPEX/Poseidon and Jason-1 using GPS Buoys in Bass Strait, Australia", 26(3-4), 2003, 285-304.

[8] G. Jan, Y. Menard, M. Faillot, F. Lyard and E. Jeansou, "Offshore Absolute Calibration of Space-Borne Radar Altimeters", Marine Geodesy, 27(3-4), 2004, 615-629. 